\title{
Fetal Stem Vessel Thrombus
}

National Cancer Institute

\section{Source}

National Cancer Institute. Fetal Stem Vessel Thrombus. NCI Thesaurus. Code C117332.

A focus of thrombus adhered to the wall of a fetal stem vessel. It can be completely or partially obstructive and may lead to avascular villi. 